\title{
POR UM PLANETA MAIS JUSTO: A BUSCA POR UMA IGUALDADE NO MERCADO DE TRABALHO ENTRE HOMENS E MULHERES
}

\author{
Paula Isabel Nobrega Introine Silva ${ }^{1}$ \\ Iranice Gonçalves Muniz**
}

\begin{abstract}
RESUMO: As questões que envolvem as políticas de gênero vão muito além de uma normatização, perpassam por questões multifacetadas, decorrência de uma plataforma baseada em preconceitos e discriminação em relação a mulher. Por isso a Organização das Nações Unidas tem como um dos Objetivos do Desenvolvimento Sustentável, a Igualdade de Gênero, estabelecendo diversas metas, dentre elas o empoderamento e o mercado de trabalho. Devido a necessidade constante de reforçar a igualdade ancorada nas diferenças, o artigo traz informações atuais da Organização Internacionais do Trabalho e do Instituto Brasileiro de Geografia e Estatística, além das fundamentações filosóficas e jurídicas sobre o assunto
\end{abstract}

Palavras-chave: Objetivos do Milênio; Igualdade de Gênero; Mulher; Trabalho; Empoderamento.

\section{FOR A MORE FAIR PLANET: THE SEARCH FOR EQUALITY IN THE LABOR MARKET BETWEEN MEN AND WOMEN}

\begin{abstract}
Gender policies issues go further normalization, beyond several questions, consequence of a platform based on prejudice and women discrimination. Therefore, United Nations Organization has as one of it Sustainable Development Goals, the Gender Equality, establishing many goals, among them empowerment and labor market. Due to theme importance and the constant need to reinforce equality anchored in differences, this article brings current information from the International Labor Organization and Brazilian Institute of Geography and Statistics about the female labor market perspectives, philosophical and legal fundaments.
\end{abstract}

Keywords: Millennium Goals; Gender Equality; Women; Labor; Empowerment.

\footnotetext{
* Mestranda em Direito e Desenvolvimento Sustentável pelo UNIPÊ. Especialista em Direito e Processo do Trabalho (UNIDERP); em Direito Civil (FADISP) e MBA em Segurança e Saúde do Trabalho (FPB). Professora e Advogada.

** Doutorado em Derecho Público pelo Universitat Pompeu Fabra, Espanha. Professora da Universidade Federal da Paraíba (UFPB) e do Centro universitário de João Pessoa (UNIPÊ).
} 


\section{INTRODUÇÃO}

Um dos temas mais importantes para a conquista do Desenvolvimento Econômico Sustentável envolve a igualdade de gênero e o empoderamento de todas as mulheres e meninas. Tanto que é elencando como um dos Objetivos do Milênio, elaborados pela Organização das Nações Unidas - ONU, que vai desde questões relacionadas ao empoderamento econômico e político até temas que passam pela saúde, a violência e a liberdade sexual.

Dentre tantas motivações que a problemática envolve, as principais dizem respeito a importância do trabalho, da valorização da mulher, da busca por uma igualdade real, da dificuldade de se cumprir normas já estabelecidas, isso tanto a nível mundial quanto local, pois aspectos sociológicos e culturais na maioria das vezes são muito mais fortes do que normas jurídicas existentes. Para superar isso não basta uma busca por uma igualdade formal ou até mesmo material, tem-se que quebrar barreiras que dificultam qualquer efetividade das leis e convenções que envolvem a questão de gênero.

Como a matéria econômica é imprescindível para o aumento das liberdades, principalmente quando se tratam dos grupos vulneráveis, e consequentemente para a amplitude das capacidades e conquistas dos bens da vida que pretendem almejar, surge uma inquietude em saber como estão os avanços relacionados as políticas de gênero e o mercado de trabalho, tanto no âmbito interno quanto mundial, para assim verificar o quão necessário é a superação das lacunas existentes.

Com a plataforma de buscar um planeta mais justo, o estudo tem por base os Objetivos do Desenvolvimento Sustentável (ODS), utilizando-se especificamente o ODS $n^{\circ} 5$, que prevê a Igualdade de Gênero. Como a vertente é a análise da desigualdade no mercado de trabalho, usou-se a meta 5.5 que visa garantir a participação plena e efetiva das mulheres e a igualdade de oportunidades para a liderança em todos os níveis de tomada de decisão na vida política, econômica e pública.

O presente trabalho tem como objeto de estudo: A cooperação internacional por uma igualdade no mercado de trabalho entre homens e mulheres. O objetivo geral é discutir sobre a importância de se buscar uma igualdade abstrata e material no que refere as diferenças de sexo, trazendo para isso um arcabouço jus filosófico. Pois, só assim se tem uma amplitude do 
problema, das deficiências, progressos e retrocessos sobre o assunto, para que se possa visualizar possíveis soluções e meios para romper barreiras tão enrijecidas e instransponíveis.

Como objetivos específicos: analisar os dados oficiais da Organização Internacional do Trabalho - OIT, sobre as perspectivas sociais do emprego no mundo especificamente relacionados as mulheres, no ano de 2018; observar os dados oficiais apresentados pelo Instituto Brasileiro de Geografia e Estatística - IBGE, sobre a participação e acesso a recursos por parte das mulheres, no ano de 2018; refletir sobre as questões jurídicas e filosóficas que perpassam pela discriminação da mulher no mercado de trabalho; apreciar a importância dos objetivos do desenvolvimento sustentável bem como da participação internacional para as políticas públicas de igualdade de gênero.

A metodologia utilizada na pesquisa foi do tipo bibliográfica, por meio da utilização de doutrinas, tratados internacionais, documentos oficiais e estatísticos mais recentes da Organização Internacional do Trabalho - OIT e do Instituto Brasileiro de Geografia e Estatística - IBGE, relacionados ao problema do gênero e o mercado de trabalho, além de se pautar no caráter qualitativo e descritivo das informações obtidas.

Como pilares teóricos tem-se as obras de John Rawls, Amartya Sen, Enrique Leff e Luige Ferrajoli, onde foram abordados temas inerentes a igualdade, diferença, amplitude das liberdades, justiça, equidade, solidariedade, desenvolvimento sustentável e política.

Metodologicamente este artigo está dividido da seguinte forma: na primeira parte aborda o cenário atual das mulheres no mercado de trabalho, que a princípio traz uma análise dos dados apresentados pela OIT em um panorama internacional sobre a igualdade de gênero e o trabalho, e em seguida um subtópico sobre os indicadores brasileiros sobre gênero e as estruturas econômicas, produtivas e acesso a recursos. A segunda parte reflete-se a respeito da mulher e economia, como construir um planeta mais justo no âmbito trabalhista.

\section{O CENÁRIO ATUAL DAS MULHERES NO MERCADO DE TRABALHO}

Apesar de lento, é fato que as conquistas das mulheres no mundo do trabalho são positivas, todavia ainda longe do ideal, como demonstrado pelo relatório apresentado pela Organização Internacional do Trabalho (OIT), sobre as perspectivas sociais do emprego no mundo especificamente sobre as mulheres no ano de 2018. Perpassando pela participação das mulheres no mercado de trabalho, as taxas de desemprego ao redor do mundo e suas 


\section{Paula Isabel Nobrega Introine Silva \& Iranice Gonçalves Muniz}

probabilidades, os empregos vulneráveis que as mulheres se submetem, os empregos informais generalizados nos países emergentes e em desenvolvimento, a pobreza laboral, as diferenças sociais entre homens e mulheres e a proteção social.

Cabe lembrar da importância de se impulsionar o acesso das mulheres ao mercado de trabalho de forma digna e igualitária, uma vez que o seu empoderamento faz diminuir a pobreza e progredir frente ao desenvolvimento econômico sustentável, prova disso é a adoção na Agenda 2030 para o Desenvolvimento Sustentável, elaborada pela Organização das Nações Unidas (ONU), onde há a previsão de que todos os líderes mundiais devem obter o emprego pleno, produtivo e o trabalho descente para todas as mulheres e homens, assim como a igualdade de remuneração pelo trabalho de igual valor, meta estipulada pelo Objetivo do Desenvolvimento Sustentável 8 (ODS 8, meta 8.5), sobre a importância em se priorizar o trabalho descente e o crescimento econômico.

Além disso, estabelece como uma de suas prioridades (ODS 5), que busca a igualdade de gênero e empoderamento das mulheres e meninas. Esse estudo, especificamente analisará a questão do gênero dentro do mercado de trabalho, corroborando com a meta 5.5, que visa garantir a participação plena e efetiva das mulheres e a igualdade de oportunidades para a liderança em todos os níveis de tomada de decisão na vida política, econômica e pública.

Sendo assim um dos principais organismos internacionais responsáveis pela busca de uma maior dignidade no trabalho em âmbito mundial, é a OIT, onde por meio de recomendações, convenções internacionais e estudos constantes, auxilia e orienta os países na busca por melhores políticas públicas a serem tomadas internamente para assim progredir nos direitos sociais ali envolvidos e consequentemente nas metas estabelecidas pela Agenda 2030 da ONU.

De acordo com o estudo apresentado pela OIT, em 08 de março de 2018, reforça-se que há muitos fatores estruturante e culturais, desde da segregação por sexo em ocupações e em setores até a discriminação e estereótipos de gênero, são causadores da problemática que envolve a mulher no mundo do trabalho (OIT, 2018b, p. 5)

A análise realizada pela OIT leva em consideração os últimos 20 anos, fazendo um comparativo entre 2009 e 2018, demonstrando que apesar de pregressos ainda houveram retrocessos em determinadas regiões, decorrente da persistência dos problemas e obstáculos que impedem as mulheres de ingressarem no mercado de trabalho, principalmente em igualdade de condições, corroborando com a ONU que a comunidade internacional tem diante de si um 
dos mais prementes desafios sociais e do mercado de trabalho, que é acabar com a diferença entre os sexos no mundo do trabalho.

O primeiro ponto de destaque anunciado pela OIT está na taxa de participação da mulher no mercado de trabalho. A conclusão principal obtida no relatório é de que em escala global as mulheres têm menos probabilidades de trabalhar quando comparadas com os homens. Em 2018, a taxa mundial de participação feminina no mercado laboral é de 48,5\%, enquanto os homens possuem uma taxa de $75 \%$, uma diferença de 26,5\%. O que chama a atenção é que a redução nos últimos 28 anos foi de apenas $2 \%$, tendo sido a maior parte dela antes de 2009. A perspectiva até 2021 é que desacelere e pare, podendo até retroceder em suas conquistas, no que tange a igualdade de gênero no mercado de trabalho (OIT, 2018b, p. 6).

Essa diferença apresentada é a média mundial, há porcentagens bem maiores como menores a depender da região, da cultura, da economia, da religião, são várias facetas que envolvem a questão da desigualdade, não é meramente uma questão numérica e financeira, pelo contrário, vai muito além, aspectos antropológicos, sociológicos, políticos e históricos devem ser somados para poder se ter uma melhor visualização do problema. Analisando os resultados separadamente é perceptível que a presença da educação e das políticas públicas direcionadas a questão de gênero são importantíssimas para superação dessa lacuna ainda existente.

As políticas públicas desempenham um papel fundamental, pois nos países que adotam uma postura igualitária e que busca de fato uma equidade de gênero, faz surgir fatores que propiciam substancialmente o aumento das taxas de participação feminina, especialmente das mães, como por exemplo com a presença de políticas de assistência familiar, que busca melhorar o equilíbrio entre a vida privada e o emprego, bem como o serviços de cuidados infantis acessíveis aos pais que trabalham (OIT, 2018b, p. 7)

O segundo ponto de destaque é que as mulheres possuem maior probabilidade de ficarem desempregadas do que os homens. De acordo com o relatório a taxa mundial de desocupação feminina é de 6\%, a relação entre as taxas homem-mulher é de 1,2 em 2018, tendo como projeção para 2021 que essa situação aumente nos países em desenvolvimento e emergentes. Porém o fator mais importante relacionado com este tópico não é o número percentual, mas a qualidade dos empregos que as mulheres ocupam, pois se distancia em muito de um mercado laboral saudável. De acordo com a OIT, a taxa de desemprego não considera como prova robusta do rendimento do mercado de trabalho dos países em desenvolvimento e até dos desenvolvidos, deixando de lado a perspectiva do trabalho decente, pois a quantidade 


\section{Paula Isabel Nobrega Introine Silva \& Iranice Gonçalves Muniz}

de emprego informal, o acesso limitado aos sistemas de proteção social, faz com que se aceite qualquer oportunidade de emprego, independente das condições de trabalho, principalmente quando somados aos papéis de gênero e a discriminação no mercado de trabalho.

O que é importante ressaltar relacionado à inclusão da mulher no mercado de trabalho é a qualidade desse ingresso, ou seja, não se pode utilizar de uma inclusão injusta para resolver os casos de uma exclusão social, pois segundo Sen e Kliksberg (2010b) mesmo que haja a preocupação em estabelecer políticas públicas que visem incluir os excluídos, não se deve seguir para um processo de inclusão injusta, isto é, apesar do sujeito não estar fora do ambiente ou direito social, como demonstra as estatísticas apresentadas pela OIT, esse é aplicado de forma injusta e muitas vezes desumanas, como por exemplo o trabalho escravo ou o prestado por grande parte das mulheres no mundo, em condições degradantes ou em ambientes prejudiciais à saúde e segurança.

O terceiro ponto abordado foi o do emprego vulnerável que afeta mais as mulheres nos países em desenvolvimento. De acordo com as estatísticas da OIT mais de $42 \%$ dos trabalhadores atuam por conta própria ou em atividades familiares, categoria classificada como emprego vulnerável (OIT, 2018b, p. 9). Pois conforme o relatório sobre as Perspectivas Sociais e de Emprego no Mundo: Tendências 2018, há de se destacar que os avanços alcançados no passado no que se refere ao trabalho e decente e não vulneráveis estão paralisados desde 2012, onde cerca de 1,4 bilhão de trabalhadores estavam em empregos vulneráveis em 2017 e que 24 milhões deverão se juntar a eles até 2019. Nos países em desenvolvimento, o emprego vulnerável afeta três em cada quatro trabalhadores (OIT, 2018c, p.6).

No que se refere a questão de gênero, é observado que os homens atuam 36,2\% por conta própria, superando em 10 pontos percentuais as mulheres a nível mundial. Também demonstrou que as mulheres têm maior participação nas economias familiares, onde nos países em desenvolvimento representam 42,3\% em 2018, contra 20,2\% do emprego masculino. Nos países desenvolvidos, o número de trabalhadoras por conta própria em 2018 é de 6,9\% e das que trabalham em âmbito familiar remunerado é de 1,6\% do total dos empregos femininos.

Próximo ângulo é tangenciado a questão da informalidade no mercado de trabalho por parte das mulheres, seja nos países em desenvolvimento como nos emergentes. É muito provável que os trabalhadores que exercem atividade por conta própria e em economia familiar estejam inseridos na informalidade, por não se cadastrarem nos órgãos oficiais e nem possuírem 
carteira de trabalho formal, é o caso das trabalhadoras de auxílio familiar, não possuindo assim nenhum tipo de proteção, tanto trabalhista quanto previdenciária.

A presença feminina na informalidade nos países em desenvolvimento é excessiva tanto no cenário urbano quanto no campo. De acordo com a OIT na estatística mais recente as mulheres superam os homens na informalidade em 4,6 pontos percentuais ao incluir as trabalhadoras agrícolas e em 7,8 pontos percentuais ao excluí-las.

No que se refere a pobreza laboral, esta é generalizada entre homens e mulheres, pois em muitos países do mundo ter um emprego remunerado não basta para sair da linha da pobreza. De acordo com a OIT (2018b, p. 12), nos países emergentes e em desenvolvimento um de cada homem e mulher que trabalha vive abaixo da linha da pobreza moderada (capital por pessoa inferior a \$3,10 dólares americanos). A constatação de maior número de homens que percebem salários inferiores a linha da pobreza deve-se ao fato da baixa participação das mulheres no mercado de trabalho nos países onde apontam este comparativo.

Os baixos salários são realidades dos trabalhos vulneráveis presente em todo o mundo, todavia a questão de gênero adentra em outro panorama, da discriminação, pois não basta a precariedade, para o mesmo serviço as mulheres ganham bem menos do que os homens. Pesquisa realizada pela OIT em 2017 aponta que o salário das mulheres é em média 20\% inferior ao dos homens. Ainda sobre o tema, o documento da ONU (2017a, p. 59) intitulado “A Agenda 2030 e a Agenda Regional de Gênero: Sinergias para a igualdade na América Latina e o Caribe” aponta que, no atual contexto de crise econômica e incertezas da região, as taxas de pobreza estão aumentando e as desigualdade de gênero se aprofundando.

Enquanto isso a OIT (2018b, p. 13) conclui que, para se reduzir as diferenças entre homens e mulheres no mercado de trabalho deve-se adotar medidas formuladas especificamente para as mulheres, observada suas diferenças e circunstâncias, o que acabará por contribuir para o bem-estar da sociedade. De um modo geral é necessário que todos os países e todos os atores sociais (governo, sindicatos e empregadores) trabalhem em conjunto para concretude dos Objetivos do Desenvolvimento Sustentável através de políticas públicas que promovam o emprego feminino de qualidade, abolindo qualquer forma de preconceito e discriminação baseado em identidade de gênero e estereótipos, reduzindo as lacunas e redistribuindo o ônus desproporcional das responsabilidades com a família e cuidados que as mulheres possuem. 

ECONÔMICAS, PRODUTIVAS E ACESSO A RECURSOS.

Tomando como base a necessidade de cada país desenvolver suas políticas públicas específicas, afim de cumprir as metas estabelecidas na Agenda 2030 da ONU, o Brasil, por meio do Instituto Brasileiro de Geografia e Estatística (IBGE), divulgou em março de 2018 o estudo "Estatísticas de gênero: indicadores sociais das mulheres no Brasil”, com a intenção de reforçar a importância de produzir dados que possam ampliar os debates, trazer maiores informações sobre o tema, e corroborar com a agenda pública permanente sobre a igualdade de gênero, que possui um dos eixos estruturantes das políticas públicas brasileira (IBGE, 2018a, p. 1).

De acordo com a ONU, as estatísticas sobre as questões relacionadas a gênero devem estar baseadas nos aspectos da vida das mulheres e homens, as oportunidades ou contribuições para a sociedade. Lembrando que cada sociedade possui suas peculiaridades, influenciando as questões que rodeiam a saúde, a educação, o trabalho, a família e o bem-estar pessoal. No caso brasileiro, a presença de maiores vulnerabilidades como cor, condição social, deficiência, morar no campo ou na cidade, entre outros, geram repercussões significativas, o que reforça ainda mais as desigualdades.

No caso do objeto desse artigo, que visa avaliar as questões sobre a igualdade de gênero dentro da meta 5.5 dos ODS (mercado de trabalho), cabe retratar como o Brasil está se comportando frente as estruturas econômicas, participação em atividades produtivas e acesso a recursos, que é um dos indicadores da Agenda dos Objetivos do Desenvolvimento Sustentável (ODS), ou Agenda 2030.

O primeiro indicador analisado pelo IBGE é o número médio de horas semanais dedicadas aos cuidados de pessoas e/ou afazeres domésticos, por sexo, que monitora o Objetivo do Milênio número 5. No Brasil, em 2016, as mulheres dedicavam cerca de 73\% mais horas do que os homens aos afazeres domésticos (18,1 horas contra 10,5 horas), podendo ser aumentada essa diferença quando analisado por região, onde por exemplo no Nordeste, as mulheres se dedicam cerca de $80 \%$ a mais do que os homens (19 horas semanais), tal dado ainda pode ser maior quando analisado em conjunto com a cor ou raça e idade.

Analisando em conjunto esses dados com o do segundo indicador, proporção de ocupação em trabalho por tempo parcial, verifica-se a nítida presença da divisão sexual do 
trabalho, pois as mulheres acumulam as funções domésticas com o trabalho externo. Uma das consequências disso é que elas optam muitas vezes em trabalhar em escala reduzida, já que necessitam de tempo para os cuidados e afazeres domésticos que ainda são responsabilidade suas, na maioria dos comparativos.

Cabe ressaltar que o percentual aumenta quando cumulado com outras variáveis, como cor e região, por exemplo na região Nordeste 36,9\% das mulheres ocupam trabalho em tempo parcial, contra 22,3\% dos homens, enquanto no Sul, as mulheres ocupam 24,1\% e os homens 10,2\%. A cor da pele também influencia, a média nacional para as mulheres brancas é de 25\%, enquanto para as mulheres pretas ou pardas é de 31.3\% (IBGE, 2018a, p. 4).

Observa-se que o percentual das mulheres é exatamente o dobro dos homens, no Brasil $28,2 \%$ das mulheres que estão inseridas no mercado de trabalho, optam por trabalhar em tempo parcial, ou seja, até 30 horas semanais, enquanto que o percentual masculino é de 14,1\%, podendo como mencionado no parágrafo anterior, aumentar conforme a região, a cor ou raça, o que gera uma diferença significativa, aumentando em 6,3 pontos percentuais entre as mulheres e em 4,1 pontos percentuais entre os homens, dados esses fornecidos, no relatório de 2018, pela Pesquisa Nacional por Amostra de Domicílios Contínua 2016.

Por fim, ainda sob a análise do ODS 5, meta 5.5, os indicadores apresentados pelo IBGE (2018a, p. 4-5) ligados aos rendimentos médios do trabalho reportam que as mulheres ainda continuam recebendo cerca de 3/4 do que os homens recebem, em 2016 tendo sido de 76,5\% do salário do trabalhador do sexo masculino. Um dado que reforça o preconceito e a discriminação da mulher no trabalho é o que se refere ao nível de instrução e dos rendimentos, apontando que a diferença remuneratória é maior quando as mulheres possuem nível superior completo ou mais, recebendo 63,4\% do que os homens, no ano de 2016.

\section{MULHER E ECONOMIA: COMO CONSTRUIR UM PLANETA 50/50 NO ÂMBITO TRABALHISTA}

Como já mencionado um dos Objetivos do Milênio ou do Desenvolvimento Sustentável é a Igualdade de Gênero (Objetivo 5), o qual possui diversas metas que visam construir um planeta igualitário, desvestido de preconceitos e discriminação das mulheres e meninas nas mais diversas formas. Todavia o artigo se propõe a analisar especificamente a meta 5.5 (Garantir a 


\section{Paula Isabel Nobrega Introine Silva \& Iranice Gonçalves Muniz}

participação plena e efetiva das mulheres e a igualdade de oportunidades para a liderança em todos os níveis de tomada de decisão na vida política, econômica e pública).

Os objetivos do desenvolvimento sustentável estão interligados, com isso ao atingir um deles estar-se-á refletindo nos demais. Por exemplo, ao dar maior empoderamento as mulheres, fazendo com que elas possuam as liberdades necessárias para ampliar suas capacidades e oportunidades, fará com que conquistem maior autonomia e independência, sendo melhor para o crescimento econômico, para erradicação da pobreza (Objetivo $n^{0} 1$ ), para os problemas relacionados à fome e nutrição (Objetivo $\mathrm{n}^{\circ} 2$ ), para assegurar uma educação inclusiva e equitativa, promotora de oportunidades (Objetivo $\mathrm{n}^{0} 4$ ) e ao retirar as mulheres de empregos vulneráveis, refletirá também na promoção do crescimento econômico, sustentável e inclusivo, pautado no emprego pleno, produtivo e decente para todos (Objetivo $\mathrm{n}^{\circ}$ 8).

Esses objetivos surgiram inicialmente da Declaração do Milênio das Nações Unidas editada em 8 de setembro de 2000, com o intuito de combater a extrema pobreza, possuindo preliminarmente 8 (oito) objetivos específicos. Porém, passada a agenda de 2015, as Nações Unidas resolveram transformar os 8 objetivos em 17, o que ocorreu durante o Rio +20 , onde os países membros assumiram novos compromissos, com metas relacionados ao Desenvolvimento Sustentável. Surgindo a partir de então os Objetivos do Desenvolvimento Sustentável (ODS), com o intuito de reduzir a pobreza, realizar a promoção social e a proteção do meio ambiente, metas estabelecidas até 2030.

O ODS número 5, que prevê a eliminação de todas as formas de discriminação contra as mulheres e meninas, em todos os âmbitos e ambientes, prega o exercício em plenitude dos seus direitos, baseado na igualdade e liberdade. Mas, para que isso ocorra se faz necessário uma visão solidária do mundo, onde todos devem agir de forma coletiva para assim colaborar com o empoderamento das mulheres, que tem efeito reflexo no desenvolvimento econômico e sustentável.

De acordo com divulgação da Organização das Nações Unidas (ONU) no dia 14 de fevereiro de 2018, não há como alcançar as metas estabelecidas para a Agenda de 2030, que prevê pôr um fim na pobreza, proteger o planeta e avançar na prosperidade, sem que haja uma igualdade de gênero, pois ela perpassa por todos os demais objetivos elencados (ONU, 2018d). Os dados apresentados demonstram que mesmo nos países onde houve algum tipo de progresso, pode não ter atingido as mulheres e meninas, que são as que mais precisam dele. Além de tantas 
outras áreas onde essa evolução permanece devagar para que sejam atingidos os objetivos até 2030. (ONU, 2018d)

Um fato importante a ser lembrado é que tais Objetivos são metas pré-estabelecidas formalmente, previstos em documentos internacionais e nacionais, outra coisa é verificar o que está acontecendo na prática, qual a realidade que se encontra a sociedade no que se refere aos problemas enfrentados pela desigualdade das mulheres e meninas. A igualdade que a ONU busca é em sua dimensão ampla, que envolve a liberdade e a própria fraternidade, pois sem que todos os Estados comecem a pensar em conjunto e em realizar medidas concretas não haverá realmente como cumprir metas mínimas até 2030.

Portanto, as desigualdades que as mulheres enfrentam não são apenas um problema de índole individual, mas sim de reflexo mundial, ou melhor, social, pois para que se alcance o progresso sustentável previsto nos 17 objetivos de desenvolvimento sustentável é imprescindível que se garantam os direitos e liberdades das mulheres e meninas, porque é a única forma de se obter justiça, alcançar a inclusão, equilibrar a economia e proteger o meio ambiente, não só agora, mas para todas as gerações futuras.

Para dar maior alcance aos compromissos estabelecidos na Agenda 2030, a ONU Mulheres lançou a campanha "Por um planeta 50-50 em 2030: um passo decisivo pela igualdade de gênero", pois como dito é necessário uma consciência de solidariedade e união para se construir um planeta 50-50, precisando do apoio de todos os homens, mulheres, sociedade, governos, empresas, universidades e meios de comunicação, para elaborarem condutas e políticas de fato eficazes (ONU MULHERES, 2017b).

Tais tipos de iniciativas, como a campanha acima, são de extrema importância para o reforço das conquistas das mulheres e meninas, bem como das normas e convenções já pré-existentes sobre a temática. Principalmente quando ainda se está tão longe de se superar as desigualdades de gênero tanto no mercado de trabalho quanto em outros direitos e liberdades que as mulheres ainda sofrem para ter acesso.

Porque com a reestruturação de planos que busquem efetividade é que as liberdades poderão ser conquistadas, pois de acordo com o economista Amartya Sen (2010a, p. 16), para que haja desenvolvimento é necessário a correção da ausência de liberdades ocasionada, por exemplo, pela pobreza e tirania, carência de oportunidades econômicas e destituição social sistemática. Essa lacuna de liberdades substantivas pode ser consequência de apenas uma ou de várias dessas fontes usurpadoras de liberdade.

Para reforçar a ideia de que é necessário cada vez mais campanhas de empoderamento das mulheres, como políticas públicas voltadas ao tema, há de mencionar o relatório apresentado pelo Fórum Econômico Mundial de 2017. Segundo ele, o Brasil ficou na posição 


\section{Paula Isabel Nobrega Introine Silva \& Iranice Gonçalves Muniz}

$90^{\mathrm{a}}$ do ranking, uma piora no que diz respeito a igualdade entre homens e mulheres, pois em 2016 ele havia ficado na $79^{\mathrm{a}}$ e em 2015 na $85^{\mathrm{a}}$.

Todavia foi o único país da América Latina e um dos seis das 144 nações, a eliminar a desigualdade entre homens e mulheres na área de educação e na questão da saúde e sobrevivência, a diferença também está próxima do fim. Em contrapartida na questão da participação econômica ele se encontra na $83^{\mathrm{a}}$ colocação e no empoderamento político na $110^{\mathrm{a}}$ posição.

Sob a ótica global a desigualdade no mundo voltou a crescer após 10 anos de avanços, o que de acordo com o relatório será preciso 100 anos para acabar com a distância entre homens e mulheres, contra 83 anos calculados em 2016. Especificamente no que diz respeito às diferenças de gênero no mercado de trabalho ainda será preciso 217 anos contra 170 anos previstos em 2016, sem mencionar o empoderamento político, que é o que possui a lacuna maior entre os sexos. (WEF, 2017c)

Diante dessa perspectiva faz-se necessário o reequilíbrio, pois só homens e mulheres livres, dotados de oportunidades serão capazes de conquistar os bens necessários para uma vida digna e sustentável. Esse argumento decorre da constatação de que a desigualdade entre mulheres e homens afeta - e às vezes encerra prematuramente - a vida de milhões de mulheres e, de modos diferentes, restringe em altíssimo grau as liberdades substantivas para o sexo feminino. (SEN, 2010a, p. 17).

Sabe-se que o econômico é necessário para ampliar as liberdades, bem como para conseguir efetivá-las, mas ele não pode ser a única mola propulsora do desenvolvimento, pelo contrário, o conceito mais moderno sobre o tema ressalta que o desenvolvimento sustentável não deve ser baseado apenas no crescimento econômico, mas obedecer um imperativo ético da solidariedade com as gerações futuras, exigindo uma sustentabilidade social, ambiental e de viabilidade econômica, que segundo Sachs (2008, p. 13-15), apenas as soluções que considerem esses três elementos é que merecem a denominação de desenvolvimento.

Segundo Leff (2016b, p. 267), a questão do gênero e da diferença sexual tem uma perspectiva dentro das políticas do "desenvolvimento sustentável”, pois para o autor para que a sustentabilidade seja alcançada vai além da emancipação de todas as formas de dominação masculina, o desafio é "decifrar o enigma da diferença aberta pela divisão dos sexos dentro das diferentes dualidades que se cruzam e se tencionam na ontologia e na política da diferença”.

Assim, o homem usa sua força física para conseguir a supremacia na ordem social, desenvolvendo estratégias de poder - físicas, gestuais, simbólicas, jurídicas - como instrumentos de dominação. A partir de uma posição de poder em sua relação com a mulher, o homem construiu 
estratégias discursivas que funcionam como dispositivos de poder. Sem dúvida, nada legitima tais afirmações de superioridade. A política feminista emerge desses lugares preestabelecidos nas estruturas simbólicas e econômicas que encontram suas origens no intercâmbio de mulheres: em suas funções de produção e reprodução. (LEFF, 2016b, p. 271)

Sendo assim, para que o desenvolvimento seja de fato perseguido, a sociedade tem que trilhar o caminho da busca pelo aumento das liberdades, da efetivação da igualdade em sentido amplo, do respeito aos direitos humanos, isto é, por uma sociedade justa, onde se proteja a individualidade de cada ser, por sua inviolabilidade, onde nem mesmo o bem-estar de toda a sociedade pode desconsiderar.

Conforme Rawls (2016c, p. 4) em uma “sociedade justa as liberdades da cidadania igual são consideradas irrevogáveis; os direitos garantidos pela justiça não estão sujeitos a negociações políticas nem ao cálculo de interesses sociais”, sendo uma injustiça permitida apenas quando for para evitar que haja uma ainda maior. Ainda sob o prisma da justiça pautada no respeito aos direitos humanos e perseguidora das liberdades, Bobbio (2004a, p. 44) ao mencionar a dificuldade de concretude dos direitos humanos por cada sociedade levanta a justificativa de ser um problema jurídico de amplitude política, não de uma mera filosofia, pois não se trata de saber quais são esses direitos, sua natureza ou fundamento, se são naturais ou históricos, absolutos ou relativos, mas sim qual o modo mais seguro para garantir e impedir que esses direitos, previstos em declarações tão solenes, sejam continuamente violados.

É importante enaltecer essa lógica dos direitos humanos e fundamentais, ou seja, de que mais importante do que o ser, aquilo que está previsto em lei, é o dever ser, que tenta retratar as injustiças presentes na sociedade. Pois existe há muito tempo, desde da Declaração dos Direitos do Homem e do Cidadão, bem como da Revolução Francesa, um falso universalismo do direito protetivo, pois os grupos vulneráveis continuavam desprotegidos, mesmo havendo uma precisão de uma igualdade formal, tanto nas Constituições quanto em regramentos internacionais.

Pois ao colocar em vala comum a igualdade, estar-se-á desvalorizando as diferenças existentes, como as relacionadas ao sexo. Uma coisa é a igualdade legal outra é a jurídica, que visa trazer em seu arcabouço as distinções existentes em cada indivíduo, que os singularizam, para assim de fato ir-se atrás de uma plena igualdade (FERRAJOLI, 2016a, p. 73-75). Pois não se deve confundir igualdade com diferença, apesar de estar correlacionadas, pois para que de 


\section{Paula Isabel Nobrega Introine Silva \& Iranice Gonçalves Muniz}

fato exista uma igualdade abstrata é necessário que as diferenças estejam contempladas, não se deve encarar as políticas públicas e normas que diferenciem homens e mulheres como anteposto à igualdade, pelo contrário o oposto de diferença é desigualdade. (FERRAJOLI, 2016a, p. 91).

Es obvio que ningún mecanismo jurídico podrá por sí solo garantizar la igualdad de hecho entre los dos sexos, por mucho que pueda ser repensado y reformulado en función de la valorización de la diferencia. La igualdad, no sólo entre los sexos, es siempre una utopía jurídica, que continuará siendo violada mientras subsistan las razones sociales, económicas y culturales que siempre sustentan el dominio masculino.(...) El verdadero problema, que exige invención e imaginación jurídica, es la elaboración de una garantía de la diferencia que sirva de hecho para garantizar la igualdad. (FERRAJOLI, 2016a, p. 91)

Como bem lembrado por Luigi Ferrajoli, o mero inventionismo jurídico não é suficiente para expurgar as desigualdades existentes na sociedade, por mais que existam normas que prevejam e enalteçam as diferenças, como as voltadas para a Agenda 2030, em relação à igualdade de gênero. É necessário uma mudança social, de reformulação da importância de se valorizar as peculiaridades de cada indivíduo, pois por mais que o direito interno e internacional visem promover os direitos das mulheres e meninas. A igualdade pleiteada não passará de uma utopia jurídica, pelo fato de tais normas estarem sempre sendo violadas por razões sociais, econômicas e culturais, sustentadas em uma hegemonia masculina.

A perspectiva de uma igualdade material se assemelha a ideia de uma teoria de justiça, seja ela a distributiva ou a teoria da justiça social, sendo um ideal a ser alcançado por ela. Com base nessa ideia, John Ralws propõe que a teoria de Justiça como Equidade seja combinado com a igualdade de oportunidades e o princípio da diferença, pois teria uma relação com a eficácia ou seja, as vantagens que se obtém com os diversos sistemas da organização social, traduzindo em uma solução justa e marcante para o sistema democrático (LUÑO, 2005).

Mesmo sendo utópico, como se reporta Ferrajoli, a busca pela igualdade e o empoderamento das mulheres não pode nunca ser colocada a sorte do acaso, por isso que a normatização continua sendo importante para uma maior conscientização e busca de medidas eficazes que proporcionem sua aplicabilidade e tentativa de mudança social. No âmbito internacional, cabe reportar os documentos que abordam a temática. O primeiro é a Convenção sobre a eliminação de todas as formas de discriminação contra a mulher, aprovada em 1979, 
ratificada pelo Brasil em 1984, esse documento tem grande importância pois prevê uma dupla proteção, tanto no caráter repressivo-punitivo, proibindo todas as formas de discriminação, quanto no caráter positivo-promocional, voltada a promoção da igualdade (PIOVESAN, 2004b, p. 2)

Caminhando nesse contexto de documentos internacionais, a Declaração e Programa de Ação de Viena (1993) foi um marco na proteção dos direitos humanos das mulheres, pois possui um ponto específico sobre a "igualdade de condição e os direitos humanos das mulheres", reportando pontos importantíssimos como a questão da saúde, da violência, do afastamento das formas de discriminação decorrentes do sexo e preconceito cultural e extremismo religioso. Sobre a importância da Declaração de Viena Piovesan (2004b, p. 5) faz a seguinte ponderação:

(...) O legado de Viena: os direitos humanos das mulheres são parte inalienável, integral e indivisível dos direitos humanos universais. Não há direitos humanos sem a plena observância dos direitos das mulheres, ou seja, não há direitos humanos sem que metade da população mundial exerça, em igualdade de condições, os direitos mais fundamentais.

Por conseguinte, não há como se buscar uma igualdade entre homens e mulheres sem que haja uma cooperação internacional, utilizando-se para isso das normas e convenções internacionais, como por exemplo a Declaração de Viena, pois os direitos humanos previstos nesses documentos são imprescindíveis para as conquistas mundiais e o adimplemento da Agenda 2030, da Organização das Nações Unidas (ONU), bem como alcançar o maior número de seres humanos, para assim atingir uma política universal baseada na igualdade, na liberdade e nos ideais de justiça.

Pode-se dizer que nada atualmente é tão importante na economia política do desenvolvimento quanto um reconhecimento adequado da participação e da liderança política, econômica e social das mulheres. Esse é, de fato, um aspecto crucial do "desenvolvimento como liberdade". (SEN, 2010a, p. 263)

Baseado no posicionamento de Amartya Sen, do ponto de vista do desenvolvimento sustentável, é necessário o empoderamento feminino, tanto para questão do crescimento econômico quanto do desenvolvimento humano, sendo o acesso ao trabalho digno a principal ferramenta de independência e libertação das mulheres. Porém, para que se progrida nas 


\section{Paula Isabel Nobrega Introine Silva \& Iranice Gonçalves Muniz}

conquistas e no equilíbrio social é necessário que a sociedade como um todo pense de forma coletiva, solidária, desvestidas de preconceitos e discriminações, bem como de suas posições políticas e econômicas.

Há de se lembrar, mesmo que hajam diferenças culturais, sociais e religiosas, a busca por uma justiça comum deve prosperar, e independente da política pública ou normatização, os princípios a ela inerentes devem estar baseados no respeito as diferenças, na busca pela paz social e por uma ideal de justiça como equidade (RAWLS, 2003, p. 183-189). Utilizando-se da teoria da Justiça como Equidade de John Rawls, ele defende uma política voltada para diferença e igualdade de forma cooperada, retirando de si todas as loterias da sorte e as características pessoais, para escolher os princípios de justiça para reger uma sociedade democrática.

Em que sentido os cidadãos são vistos como pessoas iguais? Digamos que são vistos como iguais na medida em que se considera todos que todos têm, num grau mínimo essencial, as faculdades morais necessárias para envolver-se na cooperação social a vida toda e participar da sociedade como cidadãos iguais. Ter essas faculdades nesse grau é o que consideramos como a base da igualdade entre os cidadãos como pessoas (Teoria §77): ou seja, na medida em que vemos a sociedade como um sistema equitativo de cooperação, a base da igualdade consiste em termos, no grau mínimo necessário, as capacidades morais e outras que nos permitem participar plenamente da vida cooperativa na sociedade (RAWLS, 2003, p. 27-28)

De acordo com Rawls, para que uma sociedade cooperada consiga reger princípios e diretrizes justas, tanto internamente quanto internacionalmente, é necessário que os cidadãos utilizem das suas faculdades morais, para assim pensarem como iguais, sem preocupação com os acasos, loterias da vida, posição social ou interferências culturais e religiosas. Utilizar-se deste tipo de reflexão e raciocínio fará com que se consiga de fato elaborar um sistema equitativo de cooperação, para que todos, homens e mulheres, participem de forma plena a sociedade, com acesso as oportunidades e liberdades.

Portanto, faz-se necessário que a comunidade como um todo elabore um plano de ação que seja eficiente, não apenas amparado no direito, mas sim em políticas que visem uma reconstrução social, pois como dito, o direito sozinho não consegue avançar nas questões relacionadas à discriminação e ao preconceito. Necessita-se que haja uma mudança postural, cultural e comportamental por parte da sociedade, que os indivíduos parem de pensar de forma 
individual e comecem a racionalizar que o respeito as diferenças e a busca por uma igualdade material é o melhor para todos, para a paz social e para efetividade dos direitos humanos.

\section{CONCLUSÃO}

Os problemas relacionados a discriminação de gênero e preconceito, vão muito além de dados estatísticos e protecionismo estatal, envolvem uma questão antropológica, cultural, religiosa e sociológica. Para que haja um progresso nessa questão faz-se necessário uma análise multifacetada, e mesmo assim, não se tem a certeza que se conseguirá chegar a igualdade tão almejada. Especificamente no que se refere ao mercado de trabalho, exige-se uma análise pormenorizada e os motivos que levaram as mulheres a sair do ambiente interno familiar e adentrar no ambiente externo do mercado de trabalho.

Infelizmente o caminho para superação dos problemas relacionados a mulher e o mercado de trabalho ainda está longe de ser concretizado. De acordo com a Organização Internacional do Trabalho - OIT, em relatório divulgado em março de 2018, fazendo um comparativo com os últimos 20 anos quase não houve avanço, sem mencionar que em algumas regiões ainda retrocedeu nas conquistas até então alcançadas. Pontos relevantes como a participação feminina no mercado de trabalho, sua presença marcante na informalidade e na economia familiar, bem como sua vulnerabilidade no que se refere a permanência no emprego, são pontos ainda longe de serem resolvidos, possuindo uma enorme diferença quando comparado com os homens. Há de ressaltar que tais resultados ainda são mais agressivos quando analisados sob o prisma da região, cultura e religião, fazendo com que os percentuais aumentem drasticamente.

Apesar do Brasil ter conseguido eliminar a desigualdade entre homens e mulheres na área da educação, ainda se encontra na $90^{\mathrm{a}}$ posição do ranking divulgado pelo Forúm Econômico Mundial, que analisa a igualdade entre homens e mulheres em 144 países. E, de acordo com o Instituto Brasileiro de Geografia e Estatística, as mulheres ainda dedicam quase o dobro de horas nos cuidados de pessoas e afazeres domésticos, em decorrência disso elas acabam ocupando muito dos postos de trabalho a tempo parcial, além de continuar ganhando bem menos que os homens ao desempenharem a mesma função.

Diante de tais estatísticas e da lentidão das conquistas femininas no mercado de trabalho, principalmente quando se está diante de uma crise econômica, as fragilidades e preconceitos 
Paula Isabel Nobrega Introine Silva \& Iranice Gonçalves Muniz

aumentam mais ainda as condutas discriminatórias e desiguais, fazendo com que as normas e regramentos nacionais e internacionais se tornem ineficazes, precisando sim de maior comprometimento dos organismos internacionais e das nações para promover os direitos das mulheres, pois como dito, a conquista de um planeta 50-50 faz-se necessário a colaboração de todos e todas, trabalhando de maneira determinada, concreta e sistemática para eliminar as desigualdades de gênero, o que é imprescindível na busca do Desenvolvimento Econômico Sustentável.

A superação da barreira da desigualdade entre homens e mulheres no mercado de trabalho é fator importantíssimo para concretude dos objetivos fundamentais da República Federativa do Brasil, pois o artigo $3^{\circ}$, III da Constituição Federal prevê como um deles a erradicação da pobreza e da marginalização e da redução das desigualdades sociais e regionais, situação essa que perpassa pelo empoderamento feminino e pela ruptura dos paradigmas de identidade de gênero causadores de preconceito e discriminação.

Necessita-se nesse momento de mais respeito ao tema, as metas estabelecidas nos Objetivos do Milênio, as normas já existentes que visam ampliar as liberdades e igualdades. Pois só quando se houver um pensamento fraterno, de respeito as diferenças e de conscientização que elas são necessárias para o desenvolvimento da sociedade como um todo é que se poderá ter esperança em que um dia a utopia de igualdade sexual, assim como todas as outras formas de preconceito e discriminação, será transposta e se viverá em uma mundo alicerçado na justiça, na equidade e na liberdade real. 


\section{REFERÊNCIAS BIBLIOGRÁFICAS}

BOBBIO, Noberto. A Era dos Direitos. Rio de Janeiro: Elsevier, 2004a.

FERRAJOLI, Luigi. Derechos y garantías: la ley del más débil. Madrid: Ed. Trotta, 2016a.

INSTITUTO BRASILEIRO DE GEOGRAFIA E ESTATÍSTICA - IBGE. Estatísticas de Gênero: Indicadores sociais das mulheres no Brasil. Estudos e Pesquisas, Informações Demográficas e Socioeconômicas, n. 38, 2018a. Disponível em: <https://biblioteca.ibge.gov.br/visualizacao/livros/liv101551_informativo.pdf>. Acesso em: 17 de março de 2018.

LEFF, Enrique. A Aposta pela Vida: Imaginação sociológica e imaginários sociais nos territórios ambientais do Sul. Petrópolis: Editora Vozes, $2016 \mathrm{~b}$.

ORGANIZAÇÃO INTERNACIONAL DO TRABALHO - OIT. Perspectivas Sociales y del Empleo en el Mundo: Avance Global sobre las Tendencias del Empleo Feminino 2018. Genebra: Oficina Internacional del Trabajo, 2018b. Disponível em: <http://www.ilo.org/brasilia/noticias/WCMS_615927/lang--pt/index.htm.>. Acesso em: 15 de março de 2018.

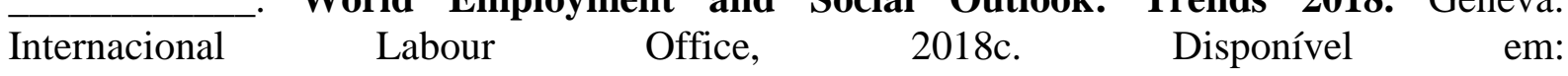
$<$ http://www.ilo.org/wcmsp5/groups/public/---dgreports/---dcomm/---

publ/documents/publication/wcms_615594.pdf>. Acesso em: 20 de março de 2018.

ORGANIZAÇÃO DAS NAÇÕES UNIDAS - ONU. Documentos Temáticos: Objetivos do Desenvolvimento Sustentável 1,2,3,5,9,14. Brasília: ONU Brasil, 2017a, p. 55-72.

. ONU: sem ações pela igualdade de gênero, mundo não alcançará objetivos globais. 2018d. Disponível em: <https://nacoesunidas.org/onu-sem-acoes-pela-igualdade-degenero-mundo-nao-alcancara-objetivos-globais/> . Acesso em: 21 de fevereiro de 2018.

ORGANIZAÇÃO DAS NAÇÕES UNIDAS MULHERES - ONU MULHERES. Planeta 5050 em 2030. Disponível em: <http://www.onumulheres.org.br/planeta5050/>. Acesso em: 19 de dezembro de 2017b.

PIOVESAN, Flavia. Mulher e o debate sobre direitos humanos no Brasil. Revista de Doutrina da $4^{\text {a }}$ Região, n. 2, 24 ago. 2004b.

SACHS, Ignacy. Desenvolvimento Includente, Sustentável e Sustentado. Rio de Janeiro: Ed. Garamond, 2008.

RAWLS, John. Uma Teoria da Justiça. São Paulo: Martins Fontes, 2016c.

Justiça como Equidade. São Paulo: Martins Fontes, 2003. 
SEN, Amartya. Desenvolvimento como Liberdade. São Paulo: Companhia das Letras, 2010a.

SEN, Amartya; KLIKSBERG, Bernardo. As Pessoas em Primeiro Lugar: a ética do desenvolvimento e os problemas do mundo globalizado. São Paulo: Companhia das Letras, 2010b.

O desenvolvimento como expansão de Capacidades. Lua Nova [online]. n.28-29, pp.313-334. 1993.

WEF. Global Gender Gap Report 2017. 2017c. Disponível em: $<$ http://reports.weforum.org/global-gender-gap-report-2017/>. Acesso em 21 de fevereiro de 2018. 